\title{
Current Research Advancements in Basic and Applied Soil Remediation in China
}

\author{
Wang Yujun ${ }^{1}\left[\right.$ - Zhong Huan ${ }^{2} \cdot$ Gu Cheng $^{2} \cdot$ Zhou Dongmei $^{1}$
}

Received: 27 June 2019 / Accepted: 1 July 2019 / Published online: 4 July 2019

(c) Springer Science+Business Media, LLC, part of Springer Nature 2019

The rapid economic growth of China in the past 30 years has caused serious soil environmental pollution. In April 2014, the former Ministry of Environmental Protection (MEP) and Ministry of Land and Resources (MLR) of China published a joint report on the nationwide soil quality survey, stating that "the country's overall status of soil environment is not optimal; the environmental quality of soil for farming uses is concerning; and abandoned sites from industrial and mining operations present severe soil environmental problems." Soil pollution has become a major public concern in China due to the health risks, and soil environmental protection and management have become urgent tasks for China (Ministry of Environmental Protection of the People's Republic of China 2014). From 2014 to 2019, the first policy statement released by the central authorities of China each year, the No. 1 Central Document, provide comprehensive roadmaps for national ecological civilization, rural vitalization, and an action plan on prevention and control of soil pollution. The overarching goal is to promote prevention and control strategies of contaminated arable land and to pilot demonstrations of soil remediation technologies for heavy metal pollution. The report of the 19th National Congress of the Communist Party of China proposed clear strategic plans to develop an ecological civilization and rebuild a beautiful China, emphasizing on poverty alleviation and prevention and control of environmental pollution by 2020 , especially to solve the urgent soil environmental problems, and to strengthen the control and restoration of soil pollution (https://www.gov.cn/ zhuanti/2017-10/27/content_5234876.htm). The Ministry of

Wang Yujun

yjwang@issas.ac.cn

1 Key Laboratory of Soil Environment and Pollution Remediation, Institute of Soil Science, Chinese Academy of Sciences, 71st East Beijing Road, Nanjing 210008, People's Republic of China

2 State Key Laboratory Pollution Control \& Resources Reuse, School of Environment, Nanjing University, 163 Xian Lin Da Dao, Nanjing 210023, Jiangsu, People's Republic of China
Ecology and Environment (MEE) of China issued two standards, the Soil Environmental Quality-Risk control standard for Soil contamination of agricultural land and Soil Environmental Quality and the Risk Control Standard for Soil Contamination of Development Land in August 2018 (Ministry of Ecology and Environment of the People's Republic of China 2018a, b). The Ministry of Science and Technology of China implemented national key research and development programs for "prevention and control techniques for agricultural non-point source and heavy metal polluted croplands" and the "causes and treatment technologies for industrial pollution sites". The two funding programs totaled RMB 2.5 billion, which greatly accelerated the fundamental and applied basic research on prevention and control of soil environmental pollution (Xu et al. 2018).

In order to further promote interdisciplinary research and technology development, strategic policy analysis and environmental policy consulting for the construction of ecological civilization of China, the Twentieth Meeting of the Soil Environment Science Committee of Soil Science Society of China, forum on Farmland Soil Pollution and Remediation, was held in Hefei, China on August 5-7, 2018. More than 600 environmental soil science researchers from 110 universities or institutes attended the event. The three day meeting included 11 plenary presentations, 36 keynote presentations, 32 oral talks and 69 student oral talks, broadly covering the major aspects of farmland soil pollution and remediation technologies, which was a successful forum of scientific exchange and discussion on cutting edge basic research and field application of novel remediation technologies on diverse types of soil pollutants. Thirty One of outstanding papers were selected by the committee to be included in the special issue from different discipline of environmental soil science such as source identification and distribution of pollutants in soils, soil processes and the environmental effect of pollutants in soils, soil remediation and environmental behavior of emerging pollutants in soils. We hope these excellent research papers will shed light on the current 
research status and the results will help to deepen our understanding about the soil environmental chemical processes and remediation in China.

\section{References}

Ministry of Environmental Protection of the People's Republic of China (2014) The investigation communique on national soil pollution condition from ministry of environmental protection of the People's Republic of China and Ministry of Land and Resources of the People's Republic of China. Beijing, China (In Chinese)

Ministry of Ecology and Environment of the People's Republic of China (2018a) GB 15618-2018. Soil Environmental Quality-Risk control standard for Soil contamination of agricultural land, Beijing, China (In Chinese)

Ministry of Ecology and Environment of the People's Republic of China (2018b) GB 36600-2018. Soil Environmental Quality and the Risk Control Standard for Soil Contamination of Development Land. Beijing, China (In Chinese)

Xu CC, Zheng G, Lin YH (2018) Brief introduction to research projects on prevention and control of cadmium and arsenic pollution in croplands supported by National Key R\&D Program of China in 13th five-year period. J Agro-Environ Sci 37(7):1321-1325 (In Chinese)

Publisher's Note Springer Nature remains neutral with regard to jurisdictional claims in published maps and institutional affiliations. 